\title{
ORIGINAL
}

ARTICLES

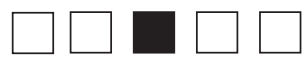

\section{Family Physician Burnout and Resilience: A Cross-sectional Analysis}

Katherine Buck, PhD, LMFT; Meredith Williamson, PhD; Stacy Ogbeide, PsyD, MS; Bethany Norberg, MD

\begin{abstract}
BACKGROUND AND OBJECTIVES: Current physician burnout levels are at historically high levels, especially in family medicine, with many factors playing a role. The goal of this study was to understand demographic, psychological, environmental, behavioral, and workplace characteristics that impact physician wellness and burnout, focusing on family medicine physicians and residents.
\end{abstract}

METHODS: Survey respondents were 295 family medicine residents and faculty members across 11 residency programs within the Residency Research Network of Texas (RRNeT). Subjects completed multiple measures to assess resilience, burnout, psychological flexibility, and workplace stress. Respondents also reported personal wellness practices and demographic information. The primary outcome variables were burnout (depersonalization, emotional exhaustion, and personal achievement) and resilience.

RESULTS: The predictor variables contributed significant variance (depersonalization $=27.1 \%$, emotional exhaustion $=39 \%$, accomplishment $=37.7 \%$, resilience $=37 \%$ ) and resulted in large effect sizes (depersonalization $f^{2}=.371$, emotional exhaustion $f^{2}=.639$, accomplishment $f^{2}=.605$, resilience $f^{2}=.587$ ) among the three burnout models and the resilience model for the sample. Similar variance and effect sizes were present for independent resident and program faculty samples, with resilience being the only outcome variable with significant differences in variance between the samples.

CONCLUSIONS: This study demonstrates the roles of both individual and organization change needed to impact provider wellness, with special attention to resilience across faculty and residents. The results of this study may inform workplace policies (ie, organizational practice change) and wellness programming and curricula (ie, individual level) for family medicine residents and program faculty.

(Fam Med. 2019;51(8):657-663.)

doi: 10.22454/FamMed.2019.424025

Published Online First July 2, 2019

nderstanding factors that influence physician well-being is a critical challenge for US health care. In this country, there has been a $10 \%$ increase in professional burnout among physicians in the last 3 years. ${ }^{1}$ Primary care physicians report high rates of burnout,

with family physicians often among the highest. Specifically, the most recent MedScape Lifestyle Report notes that more than half of family physicians are reporting burnout (54\%). ${ }^{2}$ The adverse effects of burnout are well documented. Burnout in physicians is associated with lower quality of care, reduced patient satisfaction, reduced adherence to treatment, increased medical errors, higher absenteeism and turnover rates, and increased health care costs. ${ }^{1,3-5}$ The MedScape Physician Lifestyle Report connected physician burnout with the introduction of electronic health records, increased emphasis on fee-for-service model, limited time with patients, ${ }^{6}$ and national shifts in health care policy. While burnout can influence the workplace, the workplace can also influence burnout levels in physicians. Shanafelt noted that a one-point increase in a composite leadership quality score was associated with a $3.3 \%$ decrease in burnout for physicians in that leader's department. ${ }^{7}$ Thus, higher quality proximal leaders (eg, program directors and department chairs) play an important part in influencing physician well-being.

While higher education is a protective factor for the general workforce, the same has not been true for physicians. ${ }^{8}$ Physician burnout is common to all age ranges. However, later career physicians may fare the best with respect to career distress
From the John Peter Smith Family Medicine Residency, Ft Worth, TX (Drs Buck and Norberg); Texas A\&M Health Science Center, College of Medicine, Department of Primary Care Medicine, College Station, TX (Dr Williamson); and Departments of Family \& Community Medicine and Psychiatry, University of Texas Health, San Antonio (Dr Ogbeide). 
and feelings of burnout. ${ }^{9}$ The highest rate of emotional exhaustion and burnout is present in middle-career physicians; early career physicians have the lowest satisfaction with overall career choice. ${ }^{9}$ In terms of academic medicine, burnout is the only thing other than age that was associated with intention to leave the practice of medicine. ${ }^{10}$ Thus, physician burnout may play a key role in physician workforce issues such as reduced hours and turnover (and its associated costs). Because burnout can impact family physicians in different career stages as well as across settings, studying physicians as an aggregate important.

While many have documented the risk factors of physician burnout, depression, and suicidal ideation, fewer studies have addressed the protective factors or resilience. With over 25 years of research experience on physician stress, Zwack and Schweitzer ${ }^{11}$ noted that physician resilience is "a central element of physician well-being."10,12,13 Nedrow, Steckler, and Hardman ${ }^{14}$ created a framework to connect the cultural norms of medicine (which are often linked with risk factors of burnout) with teaching resident physicians interventions that promote resiliency, such as teaching skills that promote psychological flexibility and gratitude. Resiliency can be defined through three core components: insight, self-care, and values. ${ }^{14}$ Insight can be defined as building self-awareness and managing uncertainty. Self-care can be defined as finding ways to care for oneself within a complex situation or environment. Lastly, values can be defined as identifying important life areas (eg, practicing medicine, family, health, spirituality, friendships) and engaging in activities on a consistent basis that are connected to one's identified values.

Psychological flexibility is defined as "contacting the present moment fully as a conscious human being, and based on what the situation affords, changing or persisting in behavior in the service of chosen values." ${ }^{15}$ For example, physicians building psychological flexibility in the workplace would seek to maintain awareness of their professional values (eg, competent physician, efficient physician, loved by patients, etc), and make career and patient care decisions consistent with these values within changing external situations over which they have little control (eg, complexity of patients, number of patients scheduled on panel, electronic medical record issues). Psychological flexibility is currently measured by the Acceptance and Action Questionnaire (AAQ). ${ }^{16}$ In a broad number of studies, reduced psychological flexibility (low scores on the AAQ) has been found to predict higher anxiety, greater depressive symptoms, inability to learn, and poor work performanceall of which can also negatively impact the educational and training experiences of physicians in primary care settings. ${ }^{16}$

While family physicians are at an increased risk for burnout nationally, family physicians practicing in safety net clinics may be at a higher risk than others. Physicians working in disadvantaged areas with marginalized patients have roles that expand to include advocacy and care coordination across a complex health system. ${ }^{17}$ Physicians working with migrant health services have a tenure of 3 years in these areas. ${ }^{18}$ This concern is relevant to physicians included in this study. Most of the study participants serve disadvantaged patients presenting with complex biopsychosocial concerns including physicians working within the Texas-Mexico border region where burnout is particularly high. In this study, we aimed to better understand demographic, psychological, environmental, behavioral, and workplace characteristics that impact physician wellness and burnout, focusing on family physicians and family medicine residents in Texas. We hypothesized:

1. Personal factors such as gender, ethnicity, health habits, children at home, and psychological flexibility would be associated with measures of burnout and resilience; and

2. Workplace factors such as being a young physician and workplace stress would be associated with measures of burnout and resilience.

\section{Methods}

\section{Study Participants}

Family physicians in Texas were asked to complete an online physician wellness survey through the Residency Research Network of Texas (RRNeT). RRNeT consists of 11 practice sites across Texas, including family medicine residencies and academic health centers. Participants were recruited through emails to current residents and clinical faculty, as well as community physicians with some residency affiliation. Data were collected between January and March, 2017. The only exclusion criteria were nonphysician faculty and midlevel practitioners. All survey recruitment and procedures were approved through the University of Texas San Antonio Health Sciences Centers Institutional Review Board, as well as participating sites.

\section{Survey Instrument}

A survey instrument was developed that included items to assess resilience, burnout, psychological flexibility, workplace stresses, personal wellness practices, and personal characteristics (Table 1). Survey development occurred over several months, with feedback from RRNeT members (family medicine educators in Texas).

\section{Data Analysis}

This was a cross-sectional descriptive study. Initial analyses consisted of simple frequencies and mean ratings on survey items and composite scale scores. Demographic information about the respondents as well as practice characteristics allowed us to compare group differences in survey responses across groups defined by age, gender, ethnicity, practice location and type, training level 
Table 1: Survey Domain Summary

\begin{tabular}{|l|l|l|l|}
\hline \multicolumn{1}{|c|}{ Domain } & \multicolumn{1}{|c|}{ Description } & \multicolumn{1}{c|}{ Measure } & \multicolumn{1}{c|}{ Sample Items } \\
\hline Resilience & Ability to bounce back from stress & Brief Resilience Scale ${ }^{25}$ & $\begin{array}{l}\text { "I tend to bounce back quickly after } \\
\text { hard times." }\end{array}$ \\
\hline Burnout & $\begin{array}{l}\text { Emotional exhaustion, } \\
\text { depersonalization, personal } \\
\text { accomplishment }\end{array}$ & $\begin{array}{l}\text { Maslach Burnout } \\
\text { Inventory }\end{array}$ & *proprietary \\
\hline $\begin{array}{l}\text { Psychological } \\
\text { flexibility }\end{array}$ & $\begin{array}{l}\text { Awareness of present moment, } \\
\text { ability to take action consistent } \\
\text { with values }\end{array}$ & $\begin{array}{l}\text { Primary Care Provider } \\
\text { Acceptance and Action } \\
\text { Questionnaire }\end{array}$ & $\begin{array}{l}\text { "I accept that I cannot make my } \\
\text { patients change unhealthy habits or } \\
\text { manage their disease better." }\end{array}$ \\
\hline Workplace stress & $\begin{array}{l}\text { Rating of everyday stressors in } \\
\text { primary care workplace (practice } \\
\text { management, social support, etc) }\end{array}$ & $\begin{array}{l}\text { Primary Care Provider } \\
\text { Stress Checklist }{ }^{16}\end{array}$ & $\begin{array}{l}\text { "My schedule is too tight to address } \\
\text { more than one or two problems." }\end{array}$ \\
\hline $\begin{array}{l}\text { Personal wellness } \\
\text { practices }\end{array}$ & $\begin{array}{l}\text { Specific behaviors that promote } \\
\text { wellness }\end{array}$ & $\begin{array}{l}\text { "How often do you get enough sleep?" } \\
\text { "How often do you feel grateful for } \\
\text { things or people in your life?" }\end{array}$ \\
\hline $\begin{array}{l}\text { Personal } \\
\text { characteristics }\end{array}$ & $\begin{array}{l}\text { Demographic information, } \\
\text { personal stressful events }\end{array}$ & $\begin{array}{l}\text { Age, sex, etc } \\
\text { "In the past year, have you } \\
\text { experienced a stressful life event } \\
\text { that affected your mood and/or your } \\
\text { energy?" }\end{array}$ \\
\hline
\end{tabular}

and clinical experience. Preliminary data analyses were conducted to make sure the data did not violate any statistical assumptions. Following these preliminary procedures, $t$ tests $/ \chi^{2}$ analyses were conducted to examine differences in mean scores of outcome variables among resident and nonresident physician samples. Multiple regression was also employed to determine predictors of burnout and resilience. Four regression models were created to assess the ability of the collection of demographic and psychosocial predictors to predict various aspects of burnout as measured by the MBI subscale scores (emotional exhaustion, depersonalization, and accomplishment), and resilience (Brief Resilience Scale). The collection of predictors included demographics (sex, age, non-Hispanic white ethnicity, having children at home), stress (sum of negative life events, sum of positive life events, workplace stress including practice management and administration concerns), psychological flexibility, and average frequency of healthy habits. The resilience score was used as a predictor in the models assessing burnout as an outcome. Effect sizes $\left(f^{2}\right)$ were computed for the four regression models based on Cohen's guidelines. ${ }^{19}$ Additionally, the four analyses were rerun to evaluate differences between residents and program faculty.

\section{Results}

Five hundred surveys were sent, and across 11 sites, we enrolled 357 subjects; 295 participants were included in the final regression analyses (due to missing data). Table 2 gives a demographic summary of participants. Mean age of our sample was 36.88 years (SD 10.5). Table 3 summarizes regression results. $T$-tests/ $\chi^{2}$ analyses revealed statistically significant differences between resident and nonresident physician samples for resilience $(P<.01$, mean difference $=0.67)$ and accomplishment $(P<.05$, mean difference $=2.44)$ outcome variables. Despite statistically significant differences among the two outcome variables, the differences in means between the two samples produce no differences in score interpretation among the two outcome variables.

\section{Depersonalization}

The variables entered into the first model to predict depersonalization for the total sample accounted for $27.1 \%$ of the variance ( $F$
$[11,286]=9.66, P<.001)$, and indicated a moderate effect size $\left(f^{2}=.371\right)$. The results of this model suggest that younger age, non-Hispanic white ethnicity, and lower resilience predicted increased depersonalization among the physician sample. The collection of variables accounted for $25.5 \%$ of the variance $(F$ $\left.[11,115]=3.57, P<.001\left[f^{2}=.342\right]\right)$, among program faculty and $27.2 \%$ of the variance for resident physicians $\left(F[11,158]=5.137, P<.001\left[f^{2}=.373\right]\right)$. Resilience was the only variable that significantly predicted depersonalization among program faculty while younger age and non-Hispanic white ethnicity along with resilience were significant predictors of depersonalization among resident physicians.

\section{Emotional Exhaustion}

The second regression model examined the influence of the same set of predictor variables on emotional exhaustion. These variables accounted for $39 \%$ of the variance in the emotional exhaustion model $(F[11,286]=16.609, P<.001)$. The model revealed that non-Hispanic white ethnicity, work stress related to both administrative and practice management issues, mean number of healthy habits, and resiliency were 
Table 2: Demographic Characteristics of Participants (Total Sample)

\begin{tabular}{|c|c|}
\hline Demographic & $\%(n)$ \\
\hline \multicolumn{2}{|c|}{ Sex } \\
\hline Male & $48.6(167)$ \\
\hline Female & $52.9(189)$ \\
\hline \multicolumn{2}{|c|}{ Ethnicity } \\
\hline Non-Hispanic white ethnicity & $51.5(184)$ \\
\hline Asian & $18.5(66)$ \\
\hline Hispanic & $17.9(64)$ \\
\hline African American & $4.8(17)$ \\
\hline Mixed ethnicity & $4.5(16)$ \\
\hline Other & $2.2(8)$ \\
\hline Native American & $0.6(2)$ \\
\hline \multicolumn{2}{|c|}{ Experience Level } \\
\hline$<10$ years & $61.1(218)$ \\
\hline$>10$ years & $30.5(109)$ \\
\hline \multicolumn{2}{|c|}{ Stage of Practice } \\
\hline Resident & $54.6(195)$ \\
\hline Faculty member & $32.5(116)$ \\
\hline Community physician & $11.8(42)$ \\
\hline
\end{tabular}

Table 3: Statistically Significant Predictors of Burnout Components and Resilience

\begin{tabular}{|c|c|c|}
\hline Predictor & $\beta$ Value & $P$ Value \\
\hline \multicolumn{3}{|c|}{ Predictors of Depersonalization } \\
\hline Physician age & -.256 & $<.001$ \\
\hline Physician non-Hispanic white ethnicity & .175 & .001 \\
\hline Resilience & -.199 & .001 \\
\hline \multicolumn{3}{|c|}{ Predictors of Emotional Exhaustion } \\
\hline Physician non-Hispanic white ethnicity & .132 & .006 \\
\hline Work stress, practice management & .144 & .028 \\
\hline Work stress, administrative & .256 & $<.001$ \\
\hline Mean number of healthy habits & -.140 & .011 \\
\hline Resilience & -.176 & .002 \\
\hline \multicolumn{3}{|c|}{ Predictors of Accomplishment } \\
\hline Mean number of healthy habits & .121 & .031 \\
\hline Psychological flexibility & .409 & $<.001$ \\
\hline Resilience & .144 & .012 \\
\hline \multicolumn{3}{|c|}{ Predictors of Resilience Scores } \\
\hline Physician age & -.224 & $<.001$ \\
\hline Psychological flexibility & .287 & $<.001$ \\
\hline
\end{tabular}


significant variables in the model. Thus, greater emotional exhaustion among the physician sample was significantly associated with non-Hispanic white ethnicity, greater work stress, fewer healthy habits, and lower resilience. A large effect size was evident for this model $\left(f^{2}=.639\right)$. Regarding differences between resident and program faculty, the collection of variables accounted for $38.4 \%$ of the variance $(F[11,115]=6.51 P<.001$ $\left.\left[f^{2}=.623\right]\right)$ among program faculty, and $42.3 \%$ of the variance for resident physicians $(F[11,158]=10.55$, $\left.P<.001\left[f^{2}=.733\right]\right)$. Male gender and work stress related to administrative issues were the only variables that significantly predicted emotional exhaustion among program faculty, while non-Hispanic white ethnicity, work stress related to administrative issues, mean number of healthy habits, and resiliency were significant predictors of emotional exhaustion among resident physicians.

\section{Accomplishment}

Accomplishment, another component of burnout, was the outcome variable for the third model. The predictor variables in this model produced a large effect size $\left(f^{2}=.605\right)$ and accounted for $37.7 \%$ of the variance $(F[11,286]=15.727, P<.001)$. High scores on the accomplishment subscale of the MBI were significantly associated with increased psychological flexibility, a greater average number of healthy habits, and greater resiliency among physicians. Differences between resident and program faculty suggest that the collection of variables accounted for $41.6 \%$ of the variance $(F[11,115]=7.45 P<.001$ $\left[f^{2}=.712\right]$ ) among program faculty, and $37.5 \%$ of the variance for resident physicians $(F[11,158]=8.61$, $\left.P<.001\left[f^{2}=.600\right]\right)$. Female gender and psychological flexibility were the only predictors of accomplishment among program faculty, while psychological flexibility was the only predictor of accomplishment among resident physicians.

\section{Resilience}

Resilience was the final model including the burnout subscales along with the collection of predictor variables utilized in prior models. The combination of these variables predicted $37 \%$ of the variance in the resilience model $(F[13,284]=12.815$, $P<.001)$. Resiliency among physicians was significantly associated with younger age and greater psychological flexibility. A large effect size $\left(f^{2}=.587\right)$ was computed for this model. Among resident and program faculty, the collection of variables accounted for $54.5 \%$ of the variance $(F$ $\left.[13,113]=10.40, P<.001\left[f^{2}=1.20\right]\right)$ for program faculty, and $29.1 \%$ of the variance for resident physicians $\left(F[13,156]=4.93, P<.001\left[f^{2}=.410\right]\right)$. Younger age, identifying as an ethnic minority, and psychological flexibility predicted resiliency among program faculty, while there were no statistically significant predictors of resilience among the resident physicians.

\section{Discussion}

The results of this study provide insights into the role of modifiable and nonmodifiable variables related to burnout and resilience and primary care physicians. We had two hypotheses for this study: (1) Personal factors such as gender, ethnicity, health habits, children at home, and psychological flexibility would be associated with measures of burnout and resilience; and (2) Workplace factors such as being a young physician and workplace stress would be associated with measures of burnout and resilience. The results reinforce support for personal and workplace factors impacting the variables related to burnout in this study: depersonalization, emotional expression, accomplishment, and resilience.

Regarding depersonalization, resident and program faculty who have low resiliency levels express greater depersonalization, or in other words, difficulty staying connected to patients in the present moment. If one takes into account the definition of depersonalization, the results of this study may be due to the idea that chronic feelings of depersonalization may lead to a lack of significance in one's work.

In the domain of emotional exhaustion, our data supported the importance of organizational stress. Regarding work-related stress, which impacted both groups of physicians, we suggest that workplace stress, particularly practice management and administrative concerns, are associated with emotional exhaustion for our physician sample. Specifically, participants indicated that their inability to meet the needs of their patients' multiple medical concerns during visits due to workflow difficulties and time constraints resulted in greater burnout and decreased ability to cope resiliently with life and work stress. One model proposed to explain the psychological toll of work-related stress is the Demand-Control (DC) model developed by Karasek in $1979 .{ }^{20}$ The DC model is based on the assumption that the characteristics of the job itself (job demand and lack of control/ skill use/decision authority), rather than the perception of the worker, create job strain that can predict a broad range of health and behavioral problems. Under the DM model, high demand and low control lead to psychological stress, which can then lead to development of chronic disease and behavioral problems. ${ }^{20,21}$ As a helping profession, many family physicians enter residency with the expectation that their role will be to holistically assist patients with their health care needs. First-year residents often choose their specialty due to the desire to provide continuity of care not only for individual patients, but family units as well. As a result, from the first few weeks of residency training, these young family physicians are met with contrasting expectations of their ideals of family medicine and the reality of the current workplace.

Lastly, in the area of accomplishment, higher levels of psychological flexibility were similar for resident 
and program faculty. By definition, psychological flexibility takes into account being present or mindful while in constant pursuit of one's values, especially in the face of adversity. An individual who embodies this ability will be able to develop resiliency as a by-product of being psychologically flexible and engaging in values such as improving one's health status or spending time with loved ones. Our data suggests that psychological flexibility is a personal trait that should be fostered in the ever-changing primary care environment, where physicians may have less and less control over their daily work lives due to multiple demands. Robinson, Gould, and Strosahl ${ }^{16}$ offer some suggestions for increasing psychological flexibility for physicians, such as discovering meaning in one's work and using a contextual framework to understand patients and the systems in which one works. It is of interest that psychological flexibility was not a key predictor of resilience for resident physicians, perhaps suggesting that it is a more helpful trait as physicians enter more stable points in their careers.

Regarding resilience, it is notable that especially for residents there were no statistically significant predictive variables in our model. While younger age, psychological flexibility, and identification as ethnic minority were predictive of resilience for nonresident physicians, no significant variable emerged as predictors for residents. This reflects the current state of resilience as a somewhat nebulous concept, and may also reflect the difficulties experienced across residencies of putting resilience education into a practical framework. It may also reflect the variance experienced between residencies and individualized residency experiences.

Given the results of our study, we suggest both individual and organizational approaches to the prevention of burnout and promotion of resilience in family physicians. On an individual level, our results suggest that physicians engage in practices to increase psychological flexibility. The core processes of psychological flexibility are: (1) experience the present moment; (2) strengthen connection with values; (3) sustain value-consistent action; (4) perspective taking; (5) defusion or taking a step back from unworkable rules and; (6) acceptance and focus on action. ${ }^{16}$ Examples of practices that can build these processes include (1) identifying personal and professional values and engaging in activities consistent with those values on a consistent basis; (2) viewing the private experiences (eg, negative thoughts, depressed feelings, frustration with patient or medical team, past experience with a complex patient, butterflies in stomach when engaging in a difficult patient encounter) of patients and physicians for what they are (acceptance) and focusing on engaging in actions consistent with values; and (3) perspective shifting. As with any practice, consistency with the use of skills is essential for skill development and acquisition.

From an organizational standpoint, the most important focus seems to be work stress related to administrative duties. The changes in the practice of medicine in many locations throughout the last decade have resulted in significant focus on high levels of productivity, fragmented medical care, organizational oversight by large health care organization, insurance restrictions and demands, along with decreased visit time. ${ }^{4}$ Instead of utilizing evidencebased practices and engaging in the art of medicine, family physicians find themselves performing many duties that do not require their level of training, leading to decreased satisfaction and burnout. ${ }^{4}$ The results of this study support previous research ${ }^{4}$ suggesting that systemic organizational changes are likely needed to return the joy that has been lost in the daily practice of primary care medicine.

Sinksy et al provided qualitative evidence of several innovative clinics with high levels of physician satisfaction across the country that have moved to a shared-care model..$^{22}$ These clinics have allowed family physicians to utilize their time and medical skill sets efficiently and effectively to care for patients' presenting medical concerns while other staff members work in collaboration on most other ancillary responsibilities.

While this study significantly adds to the literature on physician burnout and resilience, there are several limitations worth noting. Our sample was a cross-sectional sample of family physicians in Texas, potentially limiting the generalizability of results. Despite concerns of generalizability, previous research of primary care providers across the country has suggested similar concerns related to burnout and workplace stress, along with identifying psychological flexibility as important to physician well-being and excellent patient care. Subsequently, the sample was collected from individuals from diverse geographic, gender, and ethnic/ racial backgrounds, suggesting it is representative of the general population of academic family physicians. It should be noted that our sample of community-based physicians was too small to lend itself to separate analyses. However, it is noteworthy that many of the physicians surveyed provide care in significantly medically and financially underresourced areas. This may present additional psychological burden that may not generalize to physicians in other areas. Additionally, much of our sample represented resident physicians, and results should be interpreted cautiously with more experienced faculty physicians. Furthermore, the overall variances in the multiple regression models suggest that the predictor variables contribute to burnout and resilience among the sample; however, extrapolating individual significance of predictor variables to future samples without running similar analyses is not recommended due to generalizability limitations with multiple regression analyses. 
Overall, the results of this study suggest that individual and organizational interventions are needed to address the well-being of family physicians. This is pertinent given the relationship between physician well-being and poorer patient outcomes. ${ }^{4}$ According to our results and previous literature, interventions focused on improving practice management areas that prevent physicians from being mindful with their patients during every encounter should be the focus of health care systems. Arnetz suggests regular survey of physician wellness when evaluating organizational performance, similar to current use of patient satisfaction and financial viability. ${ }^{23}$ Interventions at the health care system level also have the capacity to improve health system performance. ${ }^{4}$ One study examining the role of stress management in reducing medical errors found a significant reduction in malpractice claims and medical errors following the intervention. ${ }^{24}$ Thus, further development and evaluation of interventions addressing the intersection of individual and organizational strategies to improve physician well-being are of utmost importance.

ACKNOWLEDGMENTS: RRNeT authors on this study included Swati Avashia, MD, Jennifer Ayers, $\mathrm{PhD}$, Jerry Kizerian, $\mathrm{PhD}$, Ronya Green, MD, Deepu George, PhD, Richard Young, MD, Sarah Holder, DO, Nina Torkelson, MD, David Edwards, MD, Marc Berger, MD, Tammy Armstrong, PsyD, Nehman Andry, $\mathrm{MD}$, Inez Cruz, $\mathrm{PhD}$, Sandra Burge, $\mathrm{PhD}$, and Ashok Kumar, MD

FUNDING STATEMENT: This project was supported by the Institute for Integration of Medicine and Science, University of Texas Health Science Center San Antonio, under the National Center for Advancing Translational Sciences, National Institutes of Health through Grant UL1 TR002645. The content is solely the responsibility of the authors and does not necessarily represent the official views of the NIH.

CORRESPONDING AUTHOR: Address correspondence to Dr Katherine Buck, 1500 South Main Street, 4th Floor OPC, Fort Worth, TX 76104. 817-702-3818. kbuck@jpshealth.org.

\section{References}

1. Shanafelt TD, Hasan O, Dyrbye LN, et al. Changes in burnout and satisfaction with work-life balance in physicians and the general US working population between 20112014. Mayo Clin Proc. 2015;90(12):16001613.

2. Peckham C. Medscape physician lifestyle report 2016: bias and burnout. Medscape. http://www.medscape.com/features/slideshow/ lifestyle/2016/public/overview?src=wnl_physrep 160127 mscpedit\&uac $=213949$ FT\&imp $\mathrm{ID}=971900 \& \mathrm{faf}=1$ \#page $=2$. Published January 13, 2016. Accessed December 10, 2017.

3. Fahrenkopf AM, Sectish TC, Barger LK, et al. Rates of medication errors among depressed and burnt out residents: prospective cohort study. BMJ. 2008;336(7642):488-491.

4. Wallace JE, Lemaire JB, Ghali WA. Physician wellness: a missing quality indicator. Lancet. 2009;374(9702):1714-1721.

5. Williams ES, Manwell LB, Konrad TR, Linzer M. The relationship of organizational culture, stress, satisfaction, and burnout with physician-reported error and suboptimal patient care: results from the MEMO study. Health Care Manage Rev. 2007;32(3):203212 .

6. Fiscella K, Epstein RM. So much to do, so little time: care for the socially disadvantaged and the 15-minute visit. Arch Intern Med. 2008;168(17):1843-1852.

7. Shanafelt TD, Gorringe G, Menaker R, et al. Impact of organizational leadership on physician burnout and satisfaction. Mayo Clin Proc. 2015;90(4):432-440

8. Shanafelt TD, Boone S, Tan L, et al. Burnout and satisfaction with work-life balance among US physicians relative to the general US population. Arch Intern Med. 2012;172(18):1377-1385.

9. Dyrbye LN, Varkey P, Boone SL, Satele DV, Sloan JA, Shanafelt TD. Physician satisfaction and burnout at different career stages. Mayo Clin Proc. 2013;88(12):1358-1367. https://doi.org/10.1016/j.mayocp.2013.07.016

10. Shanafelt TD, West CP, Sloan JA, et al. Career fit and burnout among academic faculty. Arch Intern Med. 2009;169(10):990-995.

11. Zwack J, Schweitzer J. If every fifth physician is affected by burnout, what about the other four? Resilience strategies of experienced physicians. Acad Med. 2013;88(3):382389.

12. Cooke GP, Doust JA, Steele MC. A survey of resilience, burnout, and tolerance of uncertainty in Australian general practice registrars. BMC Med Educ. 2013;13(2):2.

13. Epstein RM, Krasner MS. Physician resilience: what it means, why it matters, and how to promote it. Acad Med. 2013;88(3):301303.

14. Nedrow A, Steckler NA, Hardman J. Physician resilience and burnout: can you make the switch? Fam Pract Manag. 2013;20(1):2530
15. Working with ACT. Using mindfulness and values in the workplace to improve performance and wellbeing. https://workingwithact. com/about/about-this-site/ Accessed December 17, 2017.

16. Robinson P, Gould D, Strosahl K. Real behavior change in primary care: Improving patient outcomes and increasing job satisfaction. Oakland, CA: New Harbinger Publications; 2011.

17. Stevenson AD, Phillips CB, Anderson KJ. Resilience among doctors who work in challenging areas: a qualitative study. $\mathrm{Br} \mathrm{J}$ Gen Pract. 2011;61(588):e404-e410.

18. Singer JD, Davidson SM, Graham S, Davidson HS. Physician retention in community and migrant health centers: who stays and for how long? Med Care. 1998; 36:1198-1epstai3.

19. Cohen J. A power primer. Psychol Bull. 1992;112(1):155-159.

20. Karasek RA. Job demands, job decision latitude and mental strain: implications for job redesign. Adm Sci Q. 1979;24(2):285-307.

21. Rees H. Exposure to sheep dip and the incidence of acute symptoms in a group of Welsh sheep farmers. Occup Environ Med. 1996;53(4):258-263.

22. Sinsky CA, Willard-Grace R, Schutzbank AM, Sinsky TA, Margolius D, Bodenheimer T. In search of joy in practice: a report of 23 high-functioning primary care practices. Ann Fam Med. 2013;11(3):272-278.

23. Arnetz BB. Staff perception of the impact of health care transformation on quality of care. Int J Qual Health Care. 1999;11(4):345-351.

24. Jones JW, Barge BN, Steffy BD, Fay LM, Kunz LK, Wuebker LJ. Stress and medical malpractice: organizational risk assessment and intervention. J Appl Psychol. 1988;73(4):727-735.

25. Smith BW, Dalen J, Wiggins K, Tooley E, Christopher P, Bernard J. The brief resilience scale: assessing the ability to bounce back. Int J Behav Med. 2008;15(3):194-200.

26. Maslach C, Jackson SE, Leiter MP. Maslach Burnout iInventory Manual. Palo Alto, CA: Consulting Psychologists Press; 1996. 